\title{
OPÇÃO POR ENDIVIDAMENTO NA ESTRUTURA DE CAPITAL: EVIDÊNCIAS EM FIRMAS BRASILEIRAS
}

\section{OPTION FOR DEBT ON THE CAPITAL STRUCTURE: EVIDENCE IN BRAZILIAN FIRMS}

Ariane Firmeza Mota

Graduada em Ciências Contábeis pela Universidade Federal do Ceará; Mestranda em Administração e Controladoria pelo Programa de Pós-Graduação em Administração e Controladoria da UFC arianefmota@yahoo.com.br

\section{Antônio Carlos Dias Coelho}

Doutor em Controladoria e Contabilidade pela

Universidade de São Paulo; Professor Associado da Universidade Federal do Ceará accoelho47@gmail.com

\author{
Allan Pinheiro Holanda \\ Mestre em Administração e Controladoria pela \\ Universidade Federal do Ceará; Professor da Faculdade \\ Lourenço Filho e Faculdade Ateneu \\ allanpholanda@yahoo.com.br
}

Contextus

ISSNe 2178-9258

Organização: Comitê Científico Interinstitucional Editor Científico: Marcelle Colares Oliveira Avaliação : Double Blind Review pelo SEER/OJS Revisão: Gramatical, normativa e de formatação Recebido em 02/11/2013 Aceito em 22/02/2014 $2^{\mathrm{a}}$. versão aceita em $23 / 03 / 2014$

\section{RESUMO}

Investigou-se se empresas listadas no mercado de capitais do Brasil, em amostra de 476 empresas no período de 2000 a 2012, financiam através de endividamento seus déficits financeiros. Inova-se na estimação do déficit financeiro a partir dos modelos desenvolvidos por Shyam-Sunder e Myers (1999) e Frank e Goyal (2003). A relação déficit financeiro e variação do endividamento foi testada por meio de estimação utilizando dados em painel com hipótese que propugna a preponderância, estatisticamente significante, de financiamento do déficit financeiro por endividamento. Os resultados apontaram a rejeição da hipótese, de vez que os coeficientes situaram-se em torno de $26 \%$, indicando que, em média, apenas esta parcela do déficit financeiro é financiada por dívida; já controladas mudanças temporais e setoriais. Infere-se que a seleção da estrutura de capital pelos gestores das empresas da amostra não é feita preferencialmente como indicado pela teoria de minimização de custos de assimetria informacional.

Palavras-chave: Estrutura de capital. Custos de assimetria informacional. Endividamento. Déficit financeiro. Dados em painel.

\begin{abstract}
We investigated whether listed companies on Brazilian capital market sample of 476 firms in 20002012 period, financed by debt their financial deficits. We innovate on estimating the financial deficit following Shyam-Sunder and Myers (1999) and Frank and Goyal (2003) models. The association between financial deficit and debt increase was tested by panel data estimation; we hypothesized that occurred statistically significant preponderance in financing financial deficit by debt. The results point out to reject the hypothesis, since estimated coefficients indicated that just $26 \%$, in average, of financial deficit was funded by debt, after control time and industry effects. We infer that capital structure selection in sampled firms was not first picked as indicated by cost minimization of informational asymmetry theory.
\end{abstract}

Keywords: Capital structure. Informational asymmetry costs. Debt. Financial deficit. Panel data. 


\section{INTRODUÇÃO}

Estudos relacionados à estrutura de capital e à identificação de seus determinantes são temas pertinentes nas pesquisas na área de finanças corporativas. As pesquisas tentam explicar as decisões de financiamento das empresas e os impactos decorrentes dessas decisões em seu custo de capital e em suas medidas de risco, objetivando a escolha entre o emprego de capital próprio ou a utilização de capital de terceiros.

As teorias de estrutura ótima de capital sugerem que empresas compõem suas fontes de recursos de acordo com atributos que determinam os vários custos e benefícios associados à emissão de ações ou de dívida. Após os trabalhos seminais de Durand (1952) e Modigliani e Miller (1958 e 1963) sobre o tema, Jensen e Meckling (1976) abordaram questões relacionadas à estrutura de capital sob a perspectiva da teoria de agência. Em seguida, outros estudos que apresentaram importantes e definitivas contribuições para a temática foram o de Myers e Majluf (1984) e o de Myers (1984), que também se utilizaram de conceitos de conflitos de agência, além de apontar a assimetria de informações como importante determinante na seleção da estrutura de capital das empresas.
Nessa direção, fatores específicos das firmas - nível de tangibilidade, tamanho, rentabilidade, risco, oportunidade de crescimento e benefícios fiscais podem ser considerados como determinantes da estrutura de capital (BASTOS; NAKAMURA; BASSO, 2009). No entanto, as decisões ótimas sobre estrutura de capital não são restritas a fatores específicos das firmas, uma vez que variáveis ambientais exercem efeito moderador na decisão.

$$
\text { Características institucionais, }
$$
portanto, podem moldar a orientação do sistema financeiro e das companhias, pois os países com fraca proteção a investidores e credores tendem a ter mercado de capitais menos desenvolvidos, que podem exercer influências sobre decisões de financiamento das empresas. Já companhias com estruturas de propriedade mais concentradas assim se organizam como substituto de proteção legal (KAYO; KIMURA， 2011; PORTAL; ZANI; SILVA, 2012;), também afetando a busca de otimização do custo de capital.

Nos Estados Unidos, por exemplo, os fundos de longo prazo abastecem as necessidades das empresas, além de os bancos disporem, tradicionalmente, de alternativas de financiamento de longo prazo com as condições mais variadas possíveis (NAKAMURA; MOTA, 2002). Para os autores, essa não é a realidade que 
prevalece no cenário brasileiro, onde as empresas, mesmo de grande porte, não dispõem de linhas de crédito de longo prazo em abundância, e o seu grau de endividamento parece estar entre os mais baixos do mundo. Ademais, dependem fortemente de bancos e de mecanismos governamentais, os quais possuem, segundo divulgam, forte orientação de créditos voltados para o desenvolvimento econômico. Nesse tipo de financiamento, a avaliação da concessão do crédito se baseia em necessidades econômicas regionais ou setoriais e não na garantia de retorno de seus capitais (COELHO, 2007). É o caso do Banco Nacional de Desenvolvimento Econômico e Social - BNDES.

Nesse contexto, as empresas no Brasil têm restrição para tomar recursos de longo prazo, seja sob a forma de capital próprio, seja sob a forma de capital de terceiros, o que pode prejudicar o curso normal de suas atividades (NAKAMURA; MOTA, 2002).

Observe-se, por outro lado, que o desenvolvimento das teorias sobre estrutura ótima de capital ocorreu em ambientes econômicos e institucionais diferentes do contexto brasileiro. Esses ambientes apresentam determinadas características que não se verificam em economias em desenvolvimento, como no caso do Brasil (BRITO; CORRAR; BATISTELLA, 2007). Dado esse cenário e o arcabouço teórico sobre estrutura de capital, a presente pesquisa tem como pergunta orientadora: qual a ordem de preferência das empresas brasileiras em escolher os componentes de sua estrutura de capitais?

A hipótese, lastreada em relacionar a estrutura de capital das firmas brasileiras à preferência imposta por endividamento, com tendência ao financiamento por fontes de curto prazo, é de que as firmas brasileiras optam preferencialmente por suprir suas necessidades financeiras por meio de capital de terceiros, quer dizer, o deficit financeiro das empresas, gerado pelo crescimento de seus ativos e de sua atividade operacional, será coberto por recursos externos originando dívidas da empresa.

O objetivo da pesquisa é reinterpretar um fato consolidado na literatura de estrutura de capital em que as empresas, por decisões baseadas em estrutura ótima de capital, deveriam obter financiamento através dos próprios recursos internos (lucros retidos e passivos circulantes operacionais), e quando esses recursos não fossem suficientes elas deveriam optar pela emissão de dívidas e posteriormente pela emissão de novas ações.

\section{SUPORTE TEÓRICO}


O questionamento clássico sobre as teorias de financiamento é saber se existe uma composição de estrutura ótima de capital, estabelecendo-se a relação entre capital próprio e de terceiros, que minimiza o custo de capital da empresa, maximizando seu valor (KAYO; FAMÁ, 1997). Esse questionamento é marcado por respostas divergentes, de modo que não há como respondê-lo de forma única $\mathrm{e}$ objetiva (BASTOS; NAKAMURA, 2009). No entanto, essa questão de determinada estrutura de capital poder aumentar o valor para o acionista é uma das discussões mais importantes no campo das finanças, tanto teórica quanto empiricamente (KAYO; KIMURA, 2011).

Dois tipos básicos de modelo tentam descrever o comportamento das empresas diante das discussões da estrutura de capital. No primeiro modelo, as empresas mantêm uma meta de nível de endividamento que maximiza o seu valor de mercado. $O$ segundo baseia-se na assimetria de informações, em que a parte mais informada, os insiders, possui informação privada sobre o fluxo de retornos da empresa ou sobre suas oportunidades de investimento, o que caracteriza essa disparidade de informação (assimetria de informação) entre os agentes (ALBANEZ; VALLE; CORRAR, 2012).

As teorias sobre estrutura de capital tentam explicar o que determina a política de financiamento adotada pelas empresas. A partir da combinação de economias fiscais decorrentes do uso de dívidas e dos custos de falência esperados, originados do excesso de endividamento, é que se estabeleceu a teoria de trade-off. De acordo com a teoria, dois fatores em particular são observados nas decisões de financiamento das empresas: de um lado as economias fiscais esperadas pelo uso crescente de dívida e, do outro, os custos de falência esperados, que se manifestariam para os níveis elevados de endividamento.

A teoria do trade-off não considera explicitamente a existência de problemas de agência relacionados às decisões de estrutura de capital, mas também não a nega. Tais problemas são tidos como determinantes da estrutura de capital na teoria de pecking order (NAKAMURA et al., 2007). Como alternativa à escolha marginalista da teoria de trade-off, o modelo de pecking order de Myers (1984) descreve situação onde, sob informação assimétrica, os custos de financiamento por terceiros extrapolam qualquer benefício. Com base na Teoria da Agência, está a ideia de que os acionistas com poder de decisão tratarão de agir em benefício próprio em detrimento do interesse de terceiros. Diante desse conflito de interesses, aqueles que não influem no processo decisório tendem a se precaver através de restrições impostas nos 
contratos de emissão de títulos e de financiamento. Essas medidas afetam negativamente a capacidade da empresa de aproveitar boas oportunidades de investimento (NAKAMURA; MOTA, 2002).

$\mathrm{Na}$ teoria de pecking order, como os benefícios do endividamento são de segunda ordem, não há grau de alavancagem ótimo, e a dívida da firma passa a ser definida pela sua disponibilidade de fluxos de caixa. Para minimizar distorções, estabelece-se hierarquia das formas de financiamento, privilegiando a ordem que minimize o custo da informação assimétrica, onde recursos internos são preferíveis a externos e a emissão de dívida é preferível à emissão de ações (BRITO; LIMA, 2005).

$\mathrm{Na}$ forma forte dessa teoria, as empresas financiam seus projetos por meio de recursos internos e, caso esses recursos não sejam suficientes, utilizariam $\mathrm{o}$ endividamento para cobrir o deficit decorrente (IQUIAPAZA; AMARAL; ARAÚJO, 2008). Levando em consideração a forma fraca da teoria, certo nível de emissões de ações será aceito e, portanto, a redução dos níveis de endividamento também será plausível (FRANK; GOYAL，2003; CHIRINKO; SINGHA, 2000).

Conforme Damodaran (2004), uma razão para essa preferência é a valorização dada pelos administradores à flexibilidade e ao controle. Desse modo, as empresas não possuem metas de estrutura de capital, pois não existe interesse no aumento de capital de terceiros quando os fluxos de caixa internos são suficientes para financiar projetos futuros. Infere-se que essa preferência pode significar aversão do gestor ao risco advindo de maior grau de alavancagem, principalmente nos casos em que tal gestor é também o acionista majoritário, cenário típico do mercado brasileiro (PROCIANOY; CASELANI, 1997).

Além de previsões quanto ao nível de endividamento, as teorias de trade-off e de pecking order também sugerem duração ótima da dívida. Segundo Barclay e Smith Jr. (1995), para a teoria de trade-off, por exemplo, os negócios com maiores oportunidades de crescimento tendem a possuir mais dívidas de curto prazo para evitar problemas de investimento insuficientes, assim como empresas com maiores problemas de assimetria de informações, privilegiam financiamentos de curto prazo em razão de custos de informação associados aos empréstimos de longo prazo.

Nesse sentido, podem-se considerar os maiores custos proporcionais para se ter acesso às fontes tradicionais de financiamento de longo prazo no Brasil em virtude da exigência de projetos, de 
habilitação formal e de demora para a concessão do crédito. Existe, na prática, um único ofertante de recursos de longo prazo, o Banco Nacional de Desenvolvimento Econômico e Social BNDES (COELHO, 2007).

Além disso, pela assimetria de informação no mercado, há transferência de riqueza dos investidores antigos para os novos investidores. Nessa direção, uma vantagem da emissão de dívidas é que, como os portadores de títulos de dívida têm retorno esperado fixo, os acionistas não precisam partilhar seus lucros. As desvantagens da utilização de recursos de terceiros estão relacionadas com o grau de endividamento da empresa, que aumenta os custos de captação ou os juros a serem pagos (KAYO; FAMÁ, 1997; IQUIAPAZA; AMARAL; ARAÚJO, 2008).

O estudo associa-se à emergência de conciliar as teorias sobre estrutura de capital com as implicações do investimento endógeno, decorrente da restrição financeira em uma economia emergente como a do Brasil. As características institucionais do país podem exercer influência estatisticamente significante sobre as decisões de financiamento da estrutura de capital das empresas. Kayo e Kimura (2011) afirmam a consciência que têm da importância das características institucionais do país, como a proteção aos credores, o Estado de Direito e o nível de corrupção.

Ademais, as dificuldades para captação de recursos financeiros de longo prazo, os riscos decorrentes do mercado brasileiro, os benefícios fiscais oferecidos pela legislação tributária na utilização de recursos de terceiros, bem como o forte controle acionário de majoritários, são alguns dos aspectos a serem considerados pelos executivos financeiros nas decisões de estrutura de capitais. Desse modo, as decisões sobre estrutura de capital das empresas podem não ser apenas determinadas por fatores contextuais internos, mas também por questões que provocam preocupações básicas como risco financeiro e de controle da companhia

(PROCIANOY;

SCHNORRENBERGER, 2004).

Evidências empíricas sobre a teoria de estrutura de capitais no contexto brasileiro estão disponíveis na literatura. Brito e Lima (2005), por exemplo, objetivaram verificar se num ambiente de fraca proteção legal a origem do controlador oferece um colateral fiduciário ao investidor externo à firma. Estudando o impacto simultâneo do controle acionário, a tangibilidade, o crescimento, a rentabilidade e o risco para o período entre 1995 e 2001, os autores mostraram que as empresas de controle privado nacional se endividam mais que as de controle público 
nacional ou de controle estrangeiro, e que isso é conseguido pelo uso intensivo de dívida de curto prazo.

Medeiros e Daher (2005) verificam se a teoria de pecking order fornece explicação empírica para a estrutura de capital das empresas do Brasil. Os autores representaram o deficit financeiro como sendo a soma do investimento líquido em ativo fixo, do capital circulante líquido, dos dividendos pagos e do caixa gerado após juros e impostos. Segundo os autores, a pecking order considera que todos os componentes do deficit financeiro são exógenos, desde que dívidas saudáveis sejam emitidas. Os resultados revelaram coeficientes relativamente mais próximos da unidade, parecendo indicar que as empresas brasileiras estão mais próximas daquela teoria do que as empresas norteamericanas. Essa hipótese parece plausível se forem levados em conta, por um lado, o ainda relativamente limitado mercado acionário brasileiro com sua excessiva concentração, a baixa liquidez e as dificuldades de captação de recursos via emissão de ações, e, por outro lado, a existência de banco de fomento estatal com juros de longo prazo subsidiados.

Utilizando-se de questionário aplicado para amostra representativa de empresas brasileiras, Nakamura e Mota (2002), a fim de verificar a prática de decisões de estrutura de capital no mercado brasileiro, constataram a preferência pelo aproveitamento de lucros retidos, tal como preconizado pela teoria de pecking order, seguida pela opção de captação de novas dívidas.

Brito, Corrar e Batistella (2007) investigaram os determinantes da estrutura de capital das maiores empresas, de capital aberto e fechado, que atuam no Brasil. Constataram que a variável tamanho é significante nas empresas da amostra para explicar sua estrutura de capital. Os resultados encontrados indicaram que as maiores empresas são mais endividadas e possuem maior proporção de dívidas de longo prazo, corroborando, também, a percepção de que as grandes empresas no Brasil têm mais fácil acesso ao mercado de dívidas de longo prazo do que as pequenas, sobretudo por meio das linhas de crédito do BNDES.

Terra (2007) buscou identificar e mensurar, através da técnica de dados em painel, a influência de fatores macroeconômicos sobre o endividamento das empresas considerando uma amostra de sete países latino-americanos, inclusive o Brasil. Para o período de 1986 a 2000, os resultados contrariaram estudos anteriores, sugerindo que fatores macroeconômicos específicos de cada país não são determinantes do endividamento. $\mathrm{Na}$ verdade, fatores específicos das empresas mostraram-se mais significativos como 
indicadores da estrutura e do capital das empresas.

Iquiapaza, Amaral e Araújo (2008) reconheceram características como tamanho, lucratividade e crescimento dos ativos para explicar o financiamento do deficit financeiro das empresas, utilizando estimação por dados em painel. Os autores analisaram amostra de 313 empresas listadas na bolsa de valores brasileira (BM\&FBovespa) no período de 2000 a 2005. Os resultados sugeriram que unicamente empresas de menor tamanho, de lucratividade negativa e de baixo crescimento dos ativos apresentam aderência fraca às previsões da pecking order. Dessa forma, concluiu-se que a teoria não pode ser considerada uma teoria geral para explicar a estrutura de capital das empresas.

Otuka, Poker Jr. e Koshio (2012) analisaram como são tomadas as decisões de estrutura de capital em uma companhia do setor de energia elétrica sediada no Brasil. Especificamente, o trabalho procurou identificar quem são os principais participantes desse processo e em que condições essas decisões são tomadas. A pesquisa baseou-se na análise de informações coletadas através de entrevista com a diretoria de finanças corporativas da empresa. Os resultados encontrados indicam que a empresa adota um modelo de tomada de decisão baseado em decisões programadas, feitas com a participação de uma diretoria colegiada. Adicionalmente, verificou-se se as decisões são tomadas levando em consideração o custo e o prazo. Observou-se que a primeira opção é pelo uso de capital de terceiros, especialmente do BNDES, que tem o menor custo de longo prazo do mercado. Em seguida, a empresa faz opções de financiamento no mercado de capitais através da emissão de debêntures e, por último, pela emissão de ações.

Voltados para o agronegócio brasileiro, Bressan et al. (2009) verificaram os determinantes de endividamento das empresas de capital aberto enquadradas nesse setor. Constatou-se que as variáveis apontadas por Rajan e Zingales (1995) como relevantes na determinação do endividamento, tais como tangibilidade dos ativos, oportunidade de crescimento, tamanho e lucratividade, também foram representativas para explicar o endividamento de empresas do agronegócio listadas na BM\&FBovespa, no período de 1999 a 2005. Entre os oito tipos de índices de endividamento testados no estudo, o mais representativo para explicar a estrutura de capital das empresas foi o índice de endividamento através do mercado de longo prazo. Os resultados encontrados são condizentes com a predição da teoria de pecking order. 
Procianoy e Schnorrenberger (2004) investigaram a influência da estrutura de controle nas decisões de estrutura de capital das companhias abertas no Brasil no período de 1995 a 2000. Concluíram que existe influência estatisticamente significante da estrutura de controle acionário sobre as decisões de estrutura de capital, bem como a influência de variáveis relativas à lucratividade, tamanho, ano e setor.

Em consonância com a literatura da área, Nakamura et al. (2007) selecionaram as variáveis liquidez corrente, tamanho da empresa, rentabilidade, oportunidade de crescimento, risco de negócio, economia fiscal e crescimento de vendas, tangibilidade, coeficiente de variação e risco de falência, a fim de verificar se tais variáveis eram determinantes da estrutura de capital do mercado brasileiro. Os resultados de análise obtidos foram bastante consistentes com as teorias de pecking order e de trade-off e estão em linha com os observados em estudos similares realizados em diversos países.

Silva e Valle (2008) analisaram a estrutura de endividamento das empresas brasileiras e americanas no período de 1999 a 2003. Os resultados mostraram que as empresas brasileiras e as americanas apresentaram, respectivamente, proporção maior e crescente de dívidas de curto e longo prazo no período. No longo prazo, verificou-se, ainda, a superioridade das americanas sobre as brasileiras. Mas, no que se refere ao endividamento total, as brasileiras mostraram-se superiores às americanas. Nas regressões, encontraramse evidências de que uma maior proporção de ativos para garantia resulta em maiores níveis de dívida total e longo prazo. Também ficou evidenciado que empresas mais rentáveis e com altas taxas de despesa de depreciação tendem a apresentar menos dívidas, tanto de longo prazo como totais. Finalmente, verificou-se que empresas maiores tendem a ser mais endividadas no total.

Crisóstomo (2009) realizou pesquisa voltada para a análise da dificuldade das empresas brasileiras em financiar seus investimentos em capital físico e em inovação. Os resultados permitem considerar que a empresa brasileira, de fato, encara sérias dificuldades de financiamento externo para esses seus investimentos, como se verificou pela alta influência dos fundos internos da empresa na intensidade desses investimentos. Os problemas de assimetria de informações entre empresa e mercado de financiamento parecem ser relevantes no Brasil juntamente com a pouca proteção aos credores externos, o que deve contribuir para essa dependência de fundos internos para esses investimentos essenciais ao desenvolvimento da empresa. 
Trabalhos outros passaram a relacionar fatores específicos dos países, como os ambientes legal, institucional e econômico, às decisões de estrutura de capitais. Bastos, Nakamura e Basso (2009) investigaram os determinantes da estrutura de capital, utilizando painel de dados, para uma amostra de 388 empresas pertencentes às maiores economias da América Latina (México, Brasil, Argentina, Chile e Peru) no período de 2001 a 2006. Em primeiro lugar, o estudo analisou os determinantes da estrutura de capital por país, considerando os fatores específicos da empresa, a partir de dois níveis de endividamento (variáveis dependentes): total a valor contábil e total a valor de mercado. Depois, foi analisada a estrutura de capital para a América Latina (composta pelos cinco países), considerando também os fatores específicos da empresa: indústria, país e fatores macroeconômicos e institucionais.

Nesse trabalho sob comentário, a teoria do pecking order mostrou-se mais robusta em explicar a estrutura de capital das empresas latino-americanas. Os tipos e prazos de endividamento mostraram que há diferenças no relacionamento com as variáveis independentes e que, de fato, é relevante saber como tais variáveis impactam a estrutura de capital das empresas.
Albanez, Valle e Corrar (2012) verificaram se a presença de fatores institucionais como o acesso a fontes e a linhas diferenciadas de financiamento afeta a significância estatística e econômica da assimetria informacional, principal pressuposto da teoria de pecking order, na determinação da estrutura de capital das empresas brasileiras no período de 1997 a 2007. Constatou-se que a assimetria informacional não perdeu significância estatística e econômica no modelo proposto, após a inclusão de variáveis representativas de fatores institucionais, o que evidencia a importância da assimetria informacional na determinação da estrutura de capital de empresas brasileiras. Ademais, os resultados encontrados apoiam a teoria de pecking order, na qual essas empresas seriam menos endividadas devido à possibilidade de captar recursos por meio da emissão de ações.

Desde o trabalho seminal de Modigliani e Miller (1958), tem-se discutido na literatura acadêmica a relevância de políticas de estrutura de capital. Nota-se que os estudos não são unânimes quanto à escolha da estrutura de capital das empresas. As teorias de estrutura de capital explicam, em um momento, a escolha dessas estruturas e, em outro, não. 


\section{METODOLOGIA}

Esta pesquisa estende as análises anteriores, verificando se o deficit financeiro, definido como o montante de recursos financeiros demandados pela empresa e não supridos pela sua capacidade interna de geração de recursos (lucros retidos e passivos circulantes operacionais), será financiado no contexto brasileiro, fundamentalmente, com endividamento.

A amostra final considerou 3.323 empresas/ano, correspondente a 476 companhias de capital aberto listadas na BM\&FBovespa no período de 2000 a 2012, com exceção do setor Finanças e Seguros e Fundos em razão das peculiaridades desses setores quanto aos níveis de alavancagem financeira. Para a composição dessa amostra, foram excluídas da população $\quad$ (7.896 empresas/ano) 4.120 empresas/ano que deixaram de apresentar informações necessárias à composição das variáveis, e 453 empresas/ano que possuíam informações consideradas outliers. Tal exclusão baseou-se em Corrar, Paulo e Dias Filho (2007). Os autores afirmam que a utilização de observações extremas enviesa os resultados da regressão; as informações excluídas por tal critério estavam distantes em mais de 3 desviospadrão em relação à média, mantendo-se, portanto, $99 \%$ da amostra original. Tal critério está em linha com o preconizado pelos autores acima citados.

As informações foram coletadas do banco de dados Economática ${ }^{\circledR}$ e da página eletrônica da Comissão de Valores Mobiliários (CVM) e, em seguida, tratadas no software Stata 9.1®. A amostra, ademais, foi segregada em três grupos: o primeiro grupo, a amostra completa, formado pelas observações do período de 2000 a 2012; o segundo, composto apenas pelas observações do período de 2000 a 2007; o terceiro, formado por observações referentes ao período de 2008 a 2012.

Tal segregação derivou do fato de que decisões de endividamento tenham sido afetadas por eventos singulares ocorridos em anos específicos. Para confirmar tal influência no processamento dos modelos, foram incluídas variáveis binárias para os anos correspondentes de cada amostra de modo a verificar a possível influência de fatos temporários comuns a todas as empresas, destacando-se os períodos: o ano de 2007, que captaria ofertas públicas iniciais de ações (IPOs, sigla inglesa) extraordinárias; os anos de 2008 e 2009, que isolariam o efeito do processo de convergência das normas contábeis brasileiras às Normas Internacionais de Contabilidade (IFRS, sigla inglesa) e das possíveis decisões associadas à crise financeira global; o 
período compreendido entre 2010 e 2012 , isolando o efeito da Instrução CVM 476 de 16 de janeiro de 2009, que dispõe sobre a oferta pública de valores através de processo de captação de recursos mais célere e objetivo (CVM, 2009), facilitando o acesso de companhias brasileiras ao mercado de capitais.

Desse modo, objetiva-se examinar se tais fenômenos impactaram a forma de endividamento das empresas brasileiras, haja vista que no ano de 2007, por exemplo, 64 empresas passaram a negociar suas ações na BM\&FBovespa e conjuntamente captaram cerca de $\mathrm{R} \$ 55$ bilhões. Tal montante é excepcional tanto se comparado ao dos anos anteriores ou ao valor total de desembolsos do BNDES, principal fonte de financiamento de longo prazo das grandes empresas brasileiras (ALDRIGHI et al., 2010).

Já em 2008, a demonstração da estrutura de capital das empresas brasileiras pode ter sido impactada pelo processo de convergência às normas internacionais de contabilidade. Nos períodos de 2008 a 2009, consegue-se estabelecer análise satisfatória da relação causa-efeito. Cabe ressaltar que, em nenhum dos outros períodos posteriores é possível isolar o efeito com tanta qualidade (MACEDO; ARAÚJO; BRAGA, 2012).

Além de variáveis temporais, foram também incluídas variáveis binárias representativas de setores econômicos de modo a isolar influências na opção por endividamento, dado que há diferenças em setores específicos com mais necessidade de suprimento de recursos pela extensão de seus deficit financeiros. O setor industrial, por exemplo, se classifica como intensivo de capital (SOARES; KLOECKNER, 2006), pois exige grandes investimentos em imobilizado. Tais distinções tecnológicas causam evidente desproporcionalidade entre setores quanto à necessidade de financiamento. Incluíramse os setores econômicos com base na classificação do Economática ${ }^{\circledR}$ : Alimentos e Bebidas (ALM); Comércio e Serviços (COM); Concessões Públicas (Conp); Construção (Cons); Indústria (IND); Mineração (MIN); e Química (QUI).

Os testes foram efetivados por análise de regressão, estimados os coeficientes por dados em painel desbalanceado, preservando-se a amostra e escolhendo-se o método de estimação (pooled, efeitos fixos e efeitos aleatórios) com base nos testes de Breusch Pagan e de Hausman, que identificaram o mais apropriado. Os pressupostos da regressão foram tratados pela correção de White (homocedasticidade dos resíduos); pela admissão da normalidade dos resíduos, baseado no Teorema do Limite Central; e por meio de análise de correlação 
(multicolinearidade), não reportada no texto.

$\mathrm{Na}$ elaboração do modelo de avaliação da hipótese, define-se deficit financeiro (DEF) como o incremento de ativos que não tenham sido financiados por recursos gerados internamente - lucro abrangente e incremento de passivos

$$
\Delta \mathrm{END}_{\mathrm{it}}=\beta_{0}+\beta_{1} \mathrm{DEF}_{\mathrm{it}}+\beta_{2} \mathrm{ANO}+\beta_{3} \mathrm{SET}+\varepsilon_{\mathrm{it}}
$$

Em que:

$\checkmark \quad \triangle \mathrm{END}_{\text {it }}$ corresponde à variação do endividamento por emissão pública ou privada de dívida de curto e longo prazo da empresa i no período t;

$\checkmark \mathrm{DEF}_{\text {it }}$ corresponde ao deficit financeiro da empresa i no período t;

$\checkmark \quad \beta_{0}$, coeficiente linear do modelo, indica a variação do endividamento quando o deficit financeiro tende a zero;

$\checkmark \quad \beta_{1}$ é o coeficiente de associação entre variação do endividamento e deficit financeiro;

$\checkmark \quad \beta_{2}$ representa o conjunto de coeficientes para mensurar influências temporais (variável ANO) na variação do endividamento;

$\checkmark \quad \beta_{3}$ representa o conjunto de coeficientes para capturar influências setoriais (variável SET) na variação do endividamento;

$\checkmark \quad \varepsilon_{\text {it }}$ corresponde ao termo de erro do modelo.

$\mathrm{Na}$ hipótese de forte preferência pelo financiamento por endividamento nas decisões de estrutura de capital, espera-se que o financiamento do deficit financeiro resulte nos coeficientes $\beta_{0}=0$ e $\beta_{1}=1$, conforme evidências defendidas e apontadas por Medeiros e Daher, 2004; Chirinko e Singha, 2000 e Iquiapaza, Amaral e Araújo, 2008. De forma contrária, coeficientes $\beta$ nulos ou próximos a zero indicariam financiamento externo na forma de emissão de ações (IQUIAPAZA; AMARAL; ARAÚJO, 2008).

Estimou-se a variação anual do endividamento pela equação seguinte, em que os subscritos referem-se às empresas da amostra (i) e aos períodos atual (t) e anterior (t-1): 
$\Delta \mathrm{END}_{\mathrm{it}}=\left(\mathrm{EMP}_{\mathrm{it}}+\mathrm{FIN}_{\mathrm{it}}+\mathrm{DEB}_{\mathrm{it}}\right)-\left(\mathrm{EMP}_{\mathrm{it}-1}+\mathrm{FIN}_{\mathrm{it}-1}+\mathrm{DEB}_{\mathrm{it}-1}\right)$

Em que:

$\checkmark$ EMP corresponde a empréstimos de curto e longo prazo;

$\checkmark$ FIN corresponde a financiamentos de curto e longo prazo;

$\checkmark$ DEB corresponde a debêntures de curto e longo prazo;

Já o deficit financeiro foi estimado pela fórmula abaixo, em que os subscritos representam as empresas da amostra (i) e o período $(\mathrm{t})$ :

$\mathrm{DEF}_{\mathrm{it}}=\Delta \mathrm{AT}_{\mathrm{it}}-\mathrm{LAB}_{\mathrm{it}}-\Delta \mathrm{PCO}_{\mathrm{it}}$

Em que:

$\checkmark \quad \Delta$ AT corresponde à variação anual do Ativo Total;

$\checkmark$ LAB corresponde ao Lucro Abrangente;

$\checkmark \quad \triangle$ PCO corresponde à variação anual do passivo circulante operacional.

Para fins de avaliação empírica, a variação do endividamento e o deficit financeiro foram escalados pelo ativo total correspondente.

Inova-se na estimação do deficit financeiro, por subtrair das variações do ativo total as variações patrimoniais decorrentes da geração de caixa (lucro) da empresa, mesmo que reconhecidas diretamente no Patrimônio Líquido (PL) da empresa (COELHO; CARVALHO, 2007) - conceito definido como lucro abrangente -, o qual capta todo o incremento do PL não derivado de financiamento por capital próprio, ou seja, originado de novos capitais investidos por acionistas.

Também se subtraem das variações do ativo total as variações do passivo operacional circulante, já que tais passivos automáticos são financiamentos não derivados de decisões financeiras das empresas. Tais ajustes consideram que o financiamento automático decorrente de obrigações geradas pela atividade operacional da empresa ocorre de modo autônomo, o que não configura busca de financiamento externo (SEIDEL; KUME, 2003).

Tal procedimento permite estimar de forma isolada apenas os incrementos de ativo total que necessitam da ação do gestor em decidir que tipo de financiamento, externo à capacidade da empresa de autofinanciamento, será buscado no mercado financeiro. 
Adicionalmente, foi verificado em que medida o incremento do passivo operacional circulante impacta o financiamento do deficit financeiro das empresas (ASSAF NETO, 2006), redefinindo-se as equações (2) e (3), considerando-se que, conforme as pesquisas do gênero, são admitidos na definição desse deficit e na variação do endividamento os recursos gerados pela atividade operacional da empresa, resultando nas formulações seguintes com as variáveis já especificadas. Considerouse também o incremento de passivos operacionais circulantes na equação do endividamento, a fim de verificar a associação da variação do endividamento ao deficit, considerando tais obrigações:

$$
\begin{aligned}
& \Delta \mathrm{END} 2_{\mathrm{it}}=\left(\mathrm{EMP}_{\mathrm{it}}+\mathrm{FIN}_{\mathrm{it}}+\mathrm{DEB}_{\mathrm{it}}+\mathrm{PCO}_{\mathrm{it}}\right)-\left(\mathrm{EMP}_{\mathrm{it}-1}+\mathrm{FIN}_{\mathrm{it}-1}+\mathrm{DEB}_{\mathrm{it}-1}+\mathrm{POC}_{\mathrm{it}-}\right) \\
& \mathrm{DEF} 2=\Delta \mathrm{AT}-\mathrm{LAB}
\end{aligned}
$$

\section{RESULTADOS}

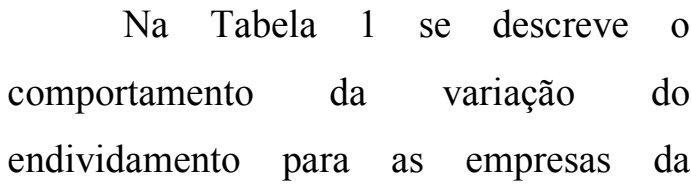
amostra (END1). Observa-se que, em média, o incremento do endividamento em relação ao ativo total foi de 3,6\% numa base anual, considerando o período analisado, sem maiores discrepâncias entre os crescimentos anuais, à exceção do ano de 2008, que teve incremento fora da curva observada, e do ano de 2003, que apresenta decremento no uso de dívidas pelas empresas brasileiras em termos médios.

Contudo, a dispersão entre empresas (a cada período) é digna de nota, quando se analisam os valores extremos e o desvio-padrão. Também se percebe que a distribuição das observações tende à normalidade, ao se confrontar média e mediana do conjunto de dados.

Vale destacar que a maior variação do endividamento ocorreu em 2008, de cerca de $8,00 \%$. Esse ano foi marcado pela atuação do BNDES, em decorrência da crise financeira mundial, por meio de forte financiamento em apoio às empresas, além da pressão exercida para a diminuição das taxas de juros da economia, em movimento político que fez com que a variação do endividamento atingisse patamares superiores (SILVA, CARDOSO; TOLEDO FILHO, 2010).

Quanto à influência dos passivos operacionais circulantes no financiamento das empresas (END2), nota-se que tais obrigações tiveram influência mais 
acentuada em relação ao passivo total na primeira quadra do período, uma vez que a média do crescimento foi predominantemente maior que os valores da variável END1.

Tabela 1 - Comportamento da variação do endividamento

\begin{tabular}{|c|c|c|c|c|c|c|c|c|c|c|c|}
\hline \multirow[b]{2}{*}{ Ano } & & \multicolumn{2}{|c|}{ Média } & \multicolumn{2}{|c|}{ Mínimo } & \multicolumn{2}{|c|}{ Máximo } & \multicolumn{2}{|c|}{ Desvio-padrão } & \multicolumn{2}{|c|}{ Mediana } \\
\hline & & END1 & END2 & END1 & END2 & END1 & END2 & END1 & END2 & END1 & END2 \\
\hline & 2000 & $3,7 \%$ & $2,6 \%$ & $-29,0 \%$ & $-36,4 \%$ & $48,5 \%$ & $47,3 \%$ & $9,6 \%$ & $9,9 \%$ & $1,7 \%$ & $2,1 \%$ \\
\hline & 2001 & $3,9 \%$ & $4,5 \%$ & $-35,0 \%$ & $-34,3 \%$ & $47,3 \%$ & $44,9 \%$ & $10,9 \%$ & $9,4 \%$ & $1,7 \%$ & $3,8 \%$ \\
\hline & 2002 & $5,1 \%$ & $6,8 \%$ & $-35,2 \%$ & $-25,0 \%$ & $44,2 \%$ & $46,7 \%$ & $11,3 \%$ & $10,6 \%$ & $4,5 \%$ & $5,1 \%$ \\
\hline & 2003 & $-1,3 \%$ & $1,8 \%$ & $-36,6 \%$ & $-25,7 \%$ & $28,9 \%$ & $45,6 \%$ & $8,8 \%$ & $9,6 \%$ & $-0,5 \%$ & $2,0 \%$ \\
\hline & 2004 & $0,6 \%$ & $3,1 \%$ & $-35,7 \%$ & $-41,6 \%$ & $41,5 \%$ & $35,7 \%$ & $9,0 \%$ & $9,7 \%$ & $0,0 \%$ & $2,6 \%$ \\
\hline & 2005 & $3,0 \%$ & $2,0 \%$ & $-30,1 \%$ & $-35,0 \%$ & $43,8 \%$ & $38,4 \%$ & $9,7 \%$ & $9,5 \%$ & $1,2 \%$ & $1,8 \%$ \\
\hline & 2006 & $3,6 \%$ & $2,5 \%$ & $-37,7 \%$ & $-37,8 \%$ & $50,4 \%$ & $46,0 \%$ & $10,4 \%$ & $10,2 \%$ & $1,4 \%$ & $2,3 \%$ \\
\hline & 2007 & $2,8 \%$ & $2,8 \%$ & $-29,5 \%$ & $-43,4 \%$ & $31,5 \%$ & $44,2 \%$ & $9,7 \%$ & $9,9 \%$ & $1,3 \%$ & $2,7 \%$ \\
\hline & 2008 & $7,7 \%$ & $5,9 \%$ & $-39,7 \%$ & $-45,8 \%$ & $56,8 \%$ & $46,3 \%$ & $13,5 \%$ & $11,0 \%$ & $5,4 \%$ & $4,8 \%$ \\
\hline & 2009 & $2,3 \%$ & $1,9 \%$ & $-37,2 \%$ & $-43,6 \%$ & $53,1 \%$ & $43,1 \%$ & $11,4 \%$ & $10,3 \%$ & $0,0 \%$ & $1,8 \%$ \\
\hline & 2010 & $5,4 \%$ & $3,3 \%$ & $-37,7 \%$ & $-32,3 \%$ & $54,3 \%$ & $38,5 \%$ & $12,1 \%$ & $9,0 \%$ & $2,6 \%$ & $2,3 \%$ \\
\hline & 2011 & $5,7 \%$ & $4,4 \%$ & $-22,1 \%$ & $-24,5 \%$ & $54,0 \%$ & $43,8 \%$ & $11,1 \%$ & $10,0 \%$ & $3,1 \%$ & $2,6 \%$ \\
\hline & 2012 & $4,8 \%$ & $3,2 \%$ & $-38,7 \%$ & $-31,0 \%$ & $49,6 \%$ & $45,3 \%$ & $11,7 \%$ & $8,4 \%$ & $2,3 \%$ & $1,9 \%$ \\
\hline Total & & $3,6 \%$ & $3,4 \%$ & $-39,7 \%$ & $-45,8 \%$ & $56,8 \%$ & $47,3 \%$ & $11,0 \%$ & $10,0 \%$ & $1,9 \%$ & $2,8 \%$ \\
\hline
\end{tabular}

Fonte: elaborada pelos autores (2014).

A Tabela 2 apresenta um déficit financeiro negativo na média de observações, com forte dispersão e mediana positiva, que indica influência de deficit particulares de grande montante. Ademais, o comportamento do deficit mostra-se errático ao longo do período, com variabilidade acentuada temporalmente.

Tal comportamento explicita situação de superavit financeiro, o qual pode ser explicado por incremento superior às necessidades operacionais de fontes internas operacionais da empresa
(Lucros Retidos e Passivos Operacionais Circulantes), em relação ao incremento médio anual dos ativos totais. Ou seja, esse superavit pode ser justificado por geração de caixa superior às necessidades operacionais e os crescimentos dos ativos podem ter sido negativos de forma preponderante no período. Ademais, o superavit financeiro pode ter tido contrapartida com redução do endividamento (SHYAM-SUNDER; MYERS, 1999; FRANK; GOYAL, 2003; MEDEIROS; DAHER, 2004). 
Tabela 2 - Comportamento da variação do deficit financeiro

\begin{tabular}{|c|c|c|c|c|c|c|c|c|c|c|}
\hline \multirow[b]{2}{*}{ Ano } & \multicolumn{2}{|c|}{ Média } & \multicolumn{2}{|c|}{ Mínimo } & \multicolumn{2}{|c|}{ Máximo } & \multicolumn{2}{|c|}{ Desvio-padrão } & \multicolumn{2}{|c|}{ Mediana } \\
\hline & DEF1 & DEF2 & DEF1 & DEF2 & DEF1 & DEF2 & DEF1 & DEF2 & DEF1 & DEF2 \\
\hline 2000 & $-1,3 \%$ & $-3,2 \%$ & $-55,7 \%$ & $-48,9 \%$ & $57,4 \%$ & $56,3 \%$ & $17,0 \%$ & $16,2 \%$ & $-1,6 \%$ & $-2,8 \%$ \\
\hline 2001 & $0,4 \%$ & $2,5 \%$ & $-55,9 \%$ & $-46,0 \%$ & $59,0 \%$ & $57,8 \%$ & $17,3 \%$ & $16,8 \%$ & $-0,1 \%$ & $2,0 \%$ \\
\hline 2002 & $3,2 \%$ & $5,6 \%$ & $-54,2 \%$ & $-46,4 \%$ & $50,5 \%$ & $54,2 \%$ & $15,1 \%$ & $14,9 \%$ & $2,9 \%$ & $5,6 \%$ \\
\hline 2003 & $-5,6 \%$ & $-7,4 \%$ & $-48,6 \%$ & $-46,9 \%$ & $53,1 \%$ & $52,4 \%$ & $17,4 \%$ & $16,6 \%$ & $-4,3 \%$ & $-6,6 \%$ \\
\hline 2004 & $0,8 \%$ & $3,7 \%$ & $-49,8 \%$ & $-47,2 \%$ & $57,7 \%$ & $57,4 \%$ & $15,3 \%$ & $15,7 \%$ & $0,8 \%$ & $3,3 \%$ \\
\hline 2005 & $1,0 \%$ & $-0,8 \%$ & $-43,0 \%$ & $-46,5 \%$ & $51,7 \%$ & $58,5 \%$ & $15,4 \%$ & $16,0 \%$ & $0,2 \%$ & $-0,2 \%$ \\
\hline 2006 & $0,8 \%$ & $1,4 \%$ & $-47,9 \%$ & $-45,1 \%$ & $58,0 \%$ & $51,2 \%$ & $15,8 \%$ & $15,6 \%$ & $0,4 \%$ & $0,2 \%$ \\
\hline 2007 & $0,8 \%$ & $1,0 \%$ & $-54,7 \%$ & $-46,1 \%$ & $48,5 \%$ & $59,1 \%$ & $17,5 \%$ & $18,1 \%$ & $-0,1 \%$ & $0,7 \%$ \\
\hline 2008 & $4,1 \%$ & $5,5 \%$ & $-54,1 \%$ & $-48,9 \%$ & $55,5 \%$ & $57,3 \%$ & $19,4 \%$ & $19,4 \%$ & $4,4 \%$ & $4,4 \%$ \\
\hline 2009 & $-5,3 \%$ & $-5,2 \%$ & $-49,5 \%$ & $-48,0 \%$ & $56,1 \%$ & $48,8 \%$ & $18,2 \%$ & $18,0 \%$ & $-4,3 \%$ & $-3,4 \%$ \\
\hline 2010 & $6,7 \%$ & $7,4 \%$ & $-47,3 \%$ & $-47,3 \%$ & $58,8 \%$ & $58,8 \%$ & $17,5 \%$ & $18,2 \%$ & $5,7 \%$ & $6,4 \%$ \\
\hline 2011 & $-1,5 \%$ & $0,1 \%$ & $-50,3 \%$ & $-47,8 \%$ & $56,0 \%$ & $57,4 \%$ & $17,5 \%$ & $19,6 \%$ & $-0,1 \%$ & $0,6 \%$ \\
\hline 2012 & $2,7 \%$ & $3,2 \%$ & $-41,8 \%$ & $-35,7 \%$ & $49,1 \%$ & $55,0 \%$ & $15,0 \%$ & $15,9 \%$ & $1,7 \%$ & $2,7 \%$ \\
\hline Total & $0,5 \%$ & $1,1 \%$ & $-55,9 \%$ & $-48,9 \%$ & $59,0 \%$ & $59,1 \%$ & $17,1 \%$ & $17,5 \%$ & $0,4 \%$ & $1,0 \%$ \\
\hline
\end{tabular}

Fonte: elaborada pelos autores (2014)

Quando analisado, na mesma Tabela 2, o comportamento do deficit financeiro, considerando-se as variações do passivo operacional circulante da empresa (DEF2), como financiamento por endividamento (incremento das obrigações da empresa), observa-se, como esperado, aumento nesse deficit. A geração de demanda de recursos decorrente do incremento do deficit financeiro, contudo, estará automaticamente financiada pela geração de passivos operacionais.

Nota-se, não obstante, que em três períodos (2000, 2003 e 2005) o deficit reduziu-se quando desconsiderado $\mathrm{o}$ passivo operacional circulante de sua composição, ou seja, esse tipo de financiamento teria influenciado na redução do deficit financeiro das empresas nesses períodos.
Na Tabela 3, expõe-se e discute-se a associação entre financiamento por dívida e deficit financeiro, ressaltando que os modelos apresentam-se adequados quanto aos ajustes dos resíduos e às medidas de consistência e eficiência, com significantes e satisfatórias medidas de poder explanatório, relatadas na apresentação de cada um dos modelos.

Observa-se que, em média, 26\% de deficit financeiro das empresas amostradas foram financiados por meio de emissão adicional de dívida, é o que indicou de forma significante o coeficiente DEF1 para a amostra completa. Nota-se que, sendo tal coeficiente bem diferente de 1 , não se identificou preponderância de financiamento do deficit pela emissão de dívidas. Vale dizer que os deficit financeiros no período foram financiados 
preferencialmente pela geração interna de recursos ou por emissão de capital próprio.

Esses números ratificam achados da pesquisa de Iquiapaza, Amaral e Araújo (2008), que, para uma amostra do período de 2000 a 2005, estimaram coeficiente estatisticamente diferente de $1(\beta=0,636)$. No entanto, contradizem a pesquisa de Shyam-Sunder e Myers (1999), os quais para uma amostra de 157 empresas encontraram $\beta=0,75$, e a pesquisa de Medeiros e Daher (2005), que, para uma amostra de 132 empresas, também encontraram coeficientes próximos da unidade, indicando que o deficit financeiro das empresas brasileiras seria coberto preferencialmente pela variação do endividamento.

Infere-se da Tabela 3, adicionalmente, que há forte dependência conjuntural nas decisões de financiamento adotadas pelos gestores, já que em oito anos da amostra há impacto significante na explicação da forma de financiamento do deficit financeiro, provavelmente originado de eventos diferentes, como se explana em seguida.

Os coeficientes apresentaram sinais negativos para os anos de 2003, 2004 e 2007, indicando níveis de financiamento por meio da emissão de dívidas significantemente menores em relação à média geral. Tais efeitos também se mostraram expressivas nos achados de Iquiapaza, Amaral e Araújo (2008) para os anos de 2003 e 2004. No ano de 2007, quando está representado pelas IPOs, o endividamento não se reduz de forma relevante para financiar incrementos de ativos. 
Tabela 3 - Escolha de endividamento na estrutura de capital

\begin{tabular}{|c|c|c|}
\hline \multicolumn{3}{|c|}{ PAINEL A - 2000 a 2012} \\
\hline Variáveis & Coeficiente & Estatística t \\
\hline DEF1 & 0,26 & $19,62 * * *$ \\
\hline 2000 & 0,03 & $2,80 * * *$ \\
\hline 2001 & 0,02 & $2,65 * * *$ \\
\hline 2002 & 0,03 & $3,13 * * *$ \\
\hline 2003 & $-0,01$ & $-1,77^{*}$ \\
\hline 2004 & $-0,02$ & $-1,76^{*}$ \\
\hline 2008 & 0,03 & $3,22 * * *$ \\
\hline 2011 & 0,02 & $2,51 * *$ \\
\hline Intercepto & 0,03 & $3,69 * * *$ \\
\hline Estatística F & \multicolumn{2}{|r|}{$43,08 * * *$} \\
\hline $\mathrm{R}^{2}$ & \multicolumn{2}{|r|}{$22,94 \%$} \\
\hline Observações-ano & \multicolumn{2}{|r|}{3.323} \\
\hline Quantidade de empresas & \multicolumn{2}{|r|}{471} \\
\hline Teste de Breusch-Pagan & \multicolumn{2}{|r|}{$51,01 * * *$} \\
\hline Teste de Hausman & \multicolumn{2}{|c|}{$54,19 * * *$} \\
\hline \multicolumn{3}{|c|}{ Processado por efeitos fixos } \\
\hline \multicolumn{3}{|c|}{ PAINEL B - 2000 a 2007} \\
\hline DEF1 & 0,25 & $20,60 * * *$ \\
\hline 2003 & $-0,04$ & $-4,84 * * *$ \\
\hline 2004 & $-0,04$ & $-4,56 * * *$ \\
\hline 2007 & $-0,01$ & $-1,66^{*}$ \\
\hline Intercepto & 0,04 & $7,14 * * *$ \\
\hline Estatística F & \multicolumn{2}{|r|}{$64,73 * * *$} \\
\hline $\mathrm{R}^{2}$ & \multicolumn{2}{|r|}{$19,34 \%$} \\
\hline Observações-ano & \multicolumn{2}{|r|}{2114} \\
\hline Quantidade de empresas & \multicolumn{2}{|r|}{388} \\
\hline Teste de Breusch-Pagan & \multicolumn{2}{|r|}{2,71} \\
\hline \multicolumn{3}{|c|}{ Processado por pooled } \\
\hline \multicolumn{3}{|c|}{ PAINEL C -2008 a 2012} \\
\hline DEF1 & 0,28 & $12,38 * * *$ \\
\hline 2008 & 0,03 & $2,99 * * *$ \\
\hline 2011 & 0,02 & $2,62 * *$ \\
\hline SET_Cons & 0,06 & $3,20 * * *$ \\
\hline Intercepto & 0,04 & $3,42 * * *$ \\
\hline Estatística $\mathrm{F}$ & \multicolumn{2}{|r|}{$214,38 * * *$} \\
\hline $\mathrm{R}^{2}$ & \multicolumn{2}{|r|}{$21,24 \%$} \\
\hline Observações-ano & \multicolumn{2}{|r|}{1209} \\
\hline Quantidade de empresas & \multicolumn{2}{|r|}{351} \\
\hline Teste de Breusch-Pagan & \multicolumn{2}{|r|}{$30,58 * * *$} \\
\hline Teste de Hausman & \multicolumn{2}{|c|}{$-88,34$} \\
\hline \multicolumn{3}{|c|}{ Processado por efeitos aleatórios } \\
\hline
\end{tabular}

***, ** e *: Significante ao nível de $1 \%, 5 \%$ e $10 \%$, respectivamente.

Variáveis ANO e SET sem significância (10\%) não reportadas.

Fonte: elaborada pelos autores (2014).

Já nos anos de 2008 e 2011 (Painel

C) há efeitos temporais positivos $\mathrm{e}$ significantes, revelando que se utilizou de maior montante de dívida no financiamento do crescimento de ativos das empresas da amostra. Entretanto, é interessante observar que a mudança de padrão contábil pode ter trazido informações antes não relatadas, o que pode ter alterado a representação da 
estrutura de capital das empresas brasileiras.

Ratifica-se que o período de transição relativo ao processo de convergência contábil deu-se entre 2008 e 2009, sendo as companhias abertas obrigadas, a partir do exercício findo de 2010, a apresentar suas demonstrações financeiras consolidadas adotando o padrão internacional (OLIVEIRA; LEMES, 2011). As observações para o ano de 2011, portanto, podem ainda ser reflexo de tal obrigatoriedade a partir de 2010 .

Exemplo de tal representação diferenciada é o registro explícito de operações de leasing no passivo das empresas e de contrapartida no ativo imobilizado (RIBEIRO; REIS; PINHEIRO, 2013). Tais alterações podem explicar o diferencial do coeficiente relativo a 2008. Araújo (2010), por exemplo, investigou a estrutura de capital das empresas brasileiras antes e depois da convergência contábil e concluiu que não houve alteração estrutural entre os dois períodos quanto ao endividamento, mas as relações de estrutura de capital e de índices de endividamento apresentaram-se diferentes.

Sobre o assunto, outros estudos já revelaram que as alterações nos padrões contábeis brasileiros convergentes às normas internacionais de contabilidade impactaram indicadores financeiros de capital de terceiros e de composição do endividamento das empresas (LUIZ; OLIVEIRA; NOGUEIRA, 2012).

Sob a perspectiva da Instrução CVM n ${ }^{\circ}$ 476/09, o ano de 2011 foi o único que se apresentou significante, não sendo possível inferir que essa regulamentação, especificamente, tenha influenciado o comportamento da opção por endividamento.

Do ponto de vista setorial, o único destaque quanto ao financiamento do deficit financeiro por endividamento foi $\mathrm{o}$ setor de construção, cujo coeficiente se revelou significante e positivo na amostra 2008/2012. Tal evidência também pode ter-se originado na crise financeira de 2008, dada a recessão na oferta de crédito privado. No entanto, o governo adotou medidas anticíclicas que contribuíram para a recuperação do crédito a partir do terceiro trimestre de 2009. Entre tais medidas, destaca-se a expansão de crédito para habitação (BRASIL, 2010), o que pode afetar diretamente o financiamento do deficit do setor em causa.

Entenda-se, além do explanado, que a significância do intercepto (por volta de $3 \%$ indica que, na média, há endividamento para as empresas, mesmo que não haja deficit financeiro explícito. A hipótese de financiamento por 
endividamento externo vinculado ao deficit não pode ser confirmada, significando que a variação no endividamento não explica preponderantemente o financiamento do deficit financeiro no período amostrado na forma proposta por Medeiros e Daher (2008).

Quando analisada a associação do deficit financeiro com o financiamento total efetuado por terceiros (de fonte financeira ou operacional - DEF2), mostrada na Tabela 4, observou-se que os montantes dos coeficientes modificaram- se; contudo, não se caracterizou alteração das inferências em relação à preferência por recursos de terceiros para $\mathrm{o}$ financiamento desse deficit.

Nesse modelo, o deficit financeiro é, na média, financiado em $21 \%$ por incremento de obrigações de terceiros, ressaltando o reduzido efeito $(5 \%)$ de passivos operacionais de giro na geração de recursos para o financiamento das necessidades de crescimento operacional das empresas brasileiras. 
Tabela 4 - Escolha de endividamento na estrutura de capital (2)

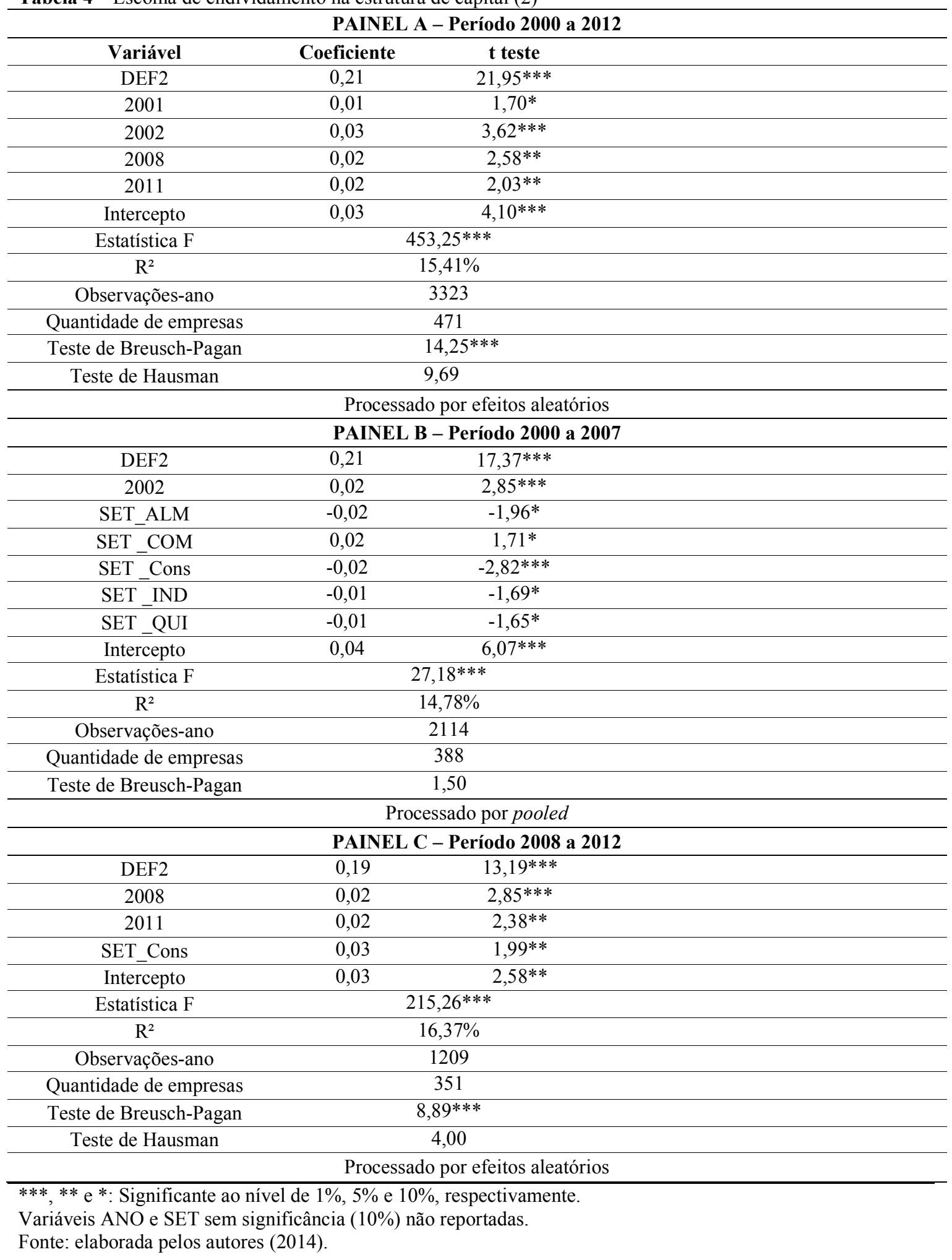


Os coeficientes também se apresentaram bem diferentes de 1 , não se alterando a participação da emissão de dívidas no financiamento do deficit financeiro, corroborando a situação de financiamento preferencial pela geração interna de recursos ou por emissão de capital próprio.

Sobressaem-se efeitos temporais menos voláteis, já que apenas 4 períodos têm impactos positivos e significantes, mantendo-se os motivos já analisados e referentes a alterações no padrão contábil brasileiro. Já os efeitos setoriais demonstram-se significantes, indicando o diferencial de créditos operacionais para os setores assinalados na Tabela 4. Induz-se que, quando o incremento do passivo operacional circulante é considerado financiamento por endividamento, o deficit financeiro passa a ser superavitário, com geração de caixa superior às necessidades operacionais.

Para as variáveis temporais, observa-se que para os anos de 2008 e 2011, explicitados no modelo anterior, há efeitos positivos e significantes, para o financiamento do crescimento de ativos pelo endividamento. Destaca-se que as observações para o ano de 2011 podem ser reflexos da obrigatoriedade a partir de 2010, cujas mudanças de padrão contábil podem ter trazido informações antes não evidenciadas, alterando a estrutura de capital das empresas brasileiras. Quanto à oferta pública de valores mobiliários com esforços restritos - Instrução CVM nº 476 - não restam inferências, uma vez que apenas o ano de 2011 apresentou-se significante.

\section{CONCLUSÕES}

O objetivo da pesquisa foi investigar se os gestores de empresas listadas no mercado de capitais brasileiro têm preferência na escolha de suas estruturas de capitais por financiamento com recursos internos, e se eles, no caso de insuficiência desses recursos, optam pela emissão de dívidas, deixando a emissão de ações como solução final, como argumentam teorias alternativas. Tal comportamento se apoiaria em alternativas para minimizar o custo de informações assimétricas, ao invés de considerar o objetivo imediato de minimização do custo de capital.

Verificou-se se a variação do endividamento está associada de forma forte ao deficit financeiro, o que implicaria preferência pelo financiamento por emissão de dívida, após o uso de recursos gerados internamente.

$\mathrm{Na}$ hipótese de forte preferência pelo financiamento por endividamento externo, esperam-se coeficientes $\beta_{0}=0$ e $\beta_{1}=1$, na forma de modelos aplicados por Medeiros e Daher (2004), Chirinko e 
Singha (2000) e Iquiapaza, Amaral e Araújo (2008).

Contudo, os coeficientes estimados para a amostra completa (2000/2012) comportaram-se de modo significantemente distintos do esperado $\left(\beta_{0}\right.$ $=0,03$ e $\beta_{1}=0,26-$ apreciando apenas o passivo financeiro - e $\beta_{1}=0,21$, ao se considerarem as obrigações totais), não revelando opção preferencial dos gestores das empresas brasileiras pela seleção de estruturas de capital suportadas por endividamento.

Por outro lado, detectou-se influência de aspectos conjunturais nas escolhas dos gestores, considerando que o comportamento temporal e setorial de tais escolhas é expressivamente diferenciado, conforme indicado pelos coeficientes associados a variáveis binárias que capturaram tais impactos.

O comportamento temporal foi constatado em outros estudos, sem que se identificassem motivos para tanto, exceto quanto à convergência do padrão contábil brasileiro ao IFRS e aos efeitos da crise mundial financeira.

Com base nos resultados, ressaltase a carência de explicação teórica consistente para o comportamento dos gestores na determinação da estrutura de capital das empresas brasileiras. Todavia, há que se advertir sobre a estrutura do sistema financeiro brasileiro com poucas opções de financiamento de longo prazo para as empresas como indicativo do baixo endividamento na composição do passivo.

A conclusão da pesquisa ficou em linha com Medeiros e Daher (2008): os gestores das empresas brasileiras não estabelecem metas para sua estrutura de capital, derivada ao longo do tempo por aspectos exógenos e conjunturais.

A estrutura de capital das empresas brasileiras, contudo, parece ser estabelecida preponderantemente como resultado da hierarquia de financiamento com recursos internos, como forma de manter assimetria informacional com os mercados financeiros, resguardando atuais acionistas.

Chirinko e Singha (2000), ressaltese, criticaram os modelos propostos para avaliar a preferência pela ordem de financiamento (recursos internos, emissão de dívida e emissão de ações), pois, segundo esses autores, os modelos não têm a capacidade de verificar se a hierarquia da seleção da estrutura de capital é obedecida em termos de timing das emissões, mas apenas respondem em termos de volumes de emissões. Ou seja, os modelos evidenciam que os volumes de emissões de ações são diferentes em cada forma de financiamento, sem revelar a sequência temporal adotada pelas empresas (MEDEIROS; DAHER, 2005). 


\section{PUBLICAÇÃO}

Prêmio de melhor artigo na área de Finanças na XXIV Jornadas LusoEspanholas de Gestão Científica 2014.

\section{REFERÊNCIAS}

ALBANEZ, A.; VALLE, M. R.; CORRAR, L. J. Fatores institucionais e assimetria informacional: influência na estrutura de capital de empresas brasileiras. Revista de Administração Mackenzie, v. 3, n. 2. p. 76-105, 2012.

ALDRIGHI, D. M. et al. As ofertas públicas iniciais na Bovespa no período recente: Características das empresas, estrutura de propriedade e de controle e desempenho. In: ENCONTRO NACIONAL DE ECONOMIA DA ASSOCIAÇÃO NACIONAL DOS CENTROS DE PÓS-GRADUAÇÃO EM ECONOMIA, 38, 2010, Salvador. Anais... Salvador: ANPEC, 2010.

ARAÚJO, B. H. A Lei 11.638/07 e os determinantes de estrutura de capital das empresas brasileiras de capital aberto no período entre 2006 e 2009. Dissertação (Mestrado em Administração), Programa de Pós-Graduação em Administração de Empresas, Universidade Presbiteriana Mackenzie, São Paulo, Brasil, 2010.

ASSAF NETO, A. Estrutura e Análise de Balanços: Um Enfoque Econômico e Financeiro. São Paulo: Atlas, 2006.

BARCLAY, M. J.; SMITH JR., C. W. The maturity structure of corporate debt.

Journal of Finance, v. 50, n. 2, p. 609631, 1995.

BASTOS, D. D.; NAKAMURA, W. T. Determinantes da estrutura de capital das companhias abertas no Brasil, México e Chile no período 2000-2006. Revista
Contabilidade \& Finanças, v. 20, n. 50, p. 75-94, 2009.

; BASSO, L. F. C.

Determinantes da estrutura de capital das companhias abertas na América Latina: um estudo empírico considerando fatores macroeconômicos e institucionais. Revista de Administração Mackenzie, v.10, n. 6, p. 47-77, 2009.

BRASIL. BNDES BANCO NACIONAL DE DESENVOLVIMENTO. Construção civil no Brasil: investimentos e desafios (organizadores: Dulce Corrêa Monteiro Filha; Ana Cristina Rodrigues da Costa; João Paulo Martin Faleiros; Bernardo Furtado Nunes). In: Perspectivas do Investimento 2010-2013.2010. Disponível em

http://www.bndes.gov.br/SiteBNDES/expo $\mathrm{rt} /$ sites/default/bndes_pt/Galerias/Arquivos /conhecimento/liv_perspectivas/09_Perspe ctivas_do_Investimento_2010_13_CONST RUCĀO_CIVIL.pdf. Acesso em: 13 mar. 2014.

BRESSAN, V. G. F. et al. Análise dos determinantes do endividamento das empresas de capital aberto do agronegócio brasileiro. Revista de Economia e Sociologia Rural, v. 47, n. 1, p. 89-122, 2009.

BRITO, G.A S.; CORRAR, L. J.; BATISTELLA, F. D. Fatores determinantes da estrutura de capital das maiores empresas que atuam no Brasil.

Revista Contabilidade \& Finanças, n. 43, p. 9-19, 2007.

BRITO, R. D.; LIMA, M. R. A escolha da estrutura de capital sob fraca garantia legal. Revista Brasileira de Economia, v. 59, n .2, p. 177-208, 2005.

CHIRINKO, R. S.; SINGHA, A. R. Testing static tradeoff against pecking order models of capital structure: a critical comment. Journal of Financial Economics, v. 58, p. 417-425, 2000. 
COELHO, A. C. D. Qualidade informacional e conservadorismo nos resultados contábeis publicados no Brasil. 2007. 240f. Tese (Doutorado em Ciências Contábeis). Faculdade de Economia, Administração e Contabilidade, Universidade de São Paulo, São Paulo, 2007.

; CARVALHO, L. N. G. Análise Conceitual de Lucro Abrangente e Lucro Operacional Corrente: Evidências no Setor Financeiro Brasileiro. BBR. Brazilian Business Review, v. 4, p. 119-139, 2007.

CORRAR, L.; PAULO, E.; DIAS FILHO, J. Análise Multivariada para os Cursos de Administração. Ciências Contábeis e Economia. São Paulo: Atlas, 2007.

CRISÓSTOMO, V. L. Dificuldades das empresas brasileiras para financiar seus investimentos em capital físico e em inovação. Revista Economia Contemporânea, v. 13, n. 2, p. 259-280, 2009.

\section{COMISSÃO DE VALORES}

MOBILIÁRIOS - CVM. Dispõe sobre as ofertas públicas de valores mobiliários distribuídas com esforços restritos e a negociação desses valores mobiliários nos mercados regulamentados. Instrução $\mathbf{n}^{\mathbf{0}}$ 476, de 16 de janeiro de 2009. Disponível em $<$ http://www.cvm.gov.br/>. Acesso em: 15 mar. 2014.

\section{DAMODARAN, A. Finanças}

corporativas: Teoria e prática. Porto

Alegre: Bookman, 2004.

DURAND, D. Cost of debt and equity funds for business: trends and problems of measurement. Conference on research on business finance, p. 215-247, New York: National Bureau of Economic Research, 1952. Disponível em $<$ http://www.nber.org/chapters/c4790.pdf > . Acesso em: 21 set. 2013.
FRANK, M. Z.; GOYAL, V. K. Testing the pecking order theory of capital structure. Journal of Financial Economics, v. 67, p. 217-248, 2003.

IQUIAPAZA, R. A.; AMARAL, H. F.; ARAÚJO, M. S. B. Testando as previsões Pecking Order Theory no financiamento das empresas brasileiras: uma nova metodologia. Revista de Administração Mackenzie, v. 9, p. 157-183, 2008.

JENSEN, M. C.; MECKLING, W. H. Theory of the firm: managerial behavior, agency costs and ownership structure. Journal of Financial Economics, v. 3, n. 4, p. 305-360, 1976.

KAYO, E. K.; FAMÁ, R. Teoria de Agência e Crescimento: Evidências Empíricas dos Efeitos Positivos e Negativos do Endividamento. Caderno de Pesquisas em Administração, v. 2, n. 5, p. 1-8, 1997.

; KIMURA, H. Hierarchical determinants of capital structure. Journal of Banking \& Finance, v. 35, p. 358-371, 2011.

LUIZ, J. C. T.; OLIVEIRA, L.;

NOGUEIRA, M. A. F. S. Análise da estrutura de capital após a convergência às normas internacionais de contabilidade. In: ENCONTRO CIENTÍFICO DE ADMINISTRAÇÃO, ECONOMIA E CONTABILIDADE, 5, 2012, Ponta Porã. Anais... Ponta Porã: ECAECO, 2012.

MACÊDO, M. A. S.; ARAÚJO, M. B. V.; BRAGA, J. P. Impacto do processo de convergência às normas internacionais de contabilidade na relevância das informações contábeis. Revista de Educação e Pesquisa em Contabilidade, v. 6, n. 4, p. 367-382, 2012.

MEDEIROS, O. R.; DAHER, C. E. Testes empíricos da Pecking Order Theory na estrutura de capital das empresas brasileiras. In: ENCONTRO NACIONAL 
DA ANPAD, 28, 2004, Curitiba. Anais... Curitiba: ANPAD, 2004.

Testando a teoria de hierarquização de fontes de financiamento nas empresas brasileiras. Revista

Contabilidade \& Finanças, n. 37, p. 3745, 2005.

Testando teorias

alternativas sobre a estrutura de capital nas empresas brasileiras. Revista de

Administração Contemporânea, v. 12, n. 1, p. 177-199, 2008.

MODIGLIANI, F.; MILLER, M. The cost of capital, corporation finance and the theory of investment. The American

Economic Review, v. 48, n. 3, p. 261-297, 1958.

Corporate income taxes

and the cost of capital: a correction.

American Economic Review, v. 53, n. 3, p. 433-443, 1963.

MYERS, S. The capital structure puzzle.

The Journal of Finance, v. 39, n. 3, p.

575-592. 1984.

; MAJLUF, N. Corporate

Financing and Investment Decisions When Firms Have Informations that Investors do not Have. Journal of Financial

Economics, v. 13, p. 187-221, 1984.

NAKAMURA, W. T. et al. Determinantes da estrutura de capital no mercado brasileiro - Análise de regressão com painel de dados no período 1999-2003.

Revista Contabilidade \& Finanças, n. 44, p. 72-85, 2007.

; MOTA, A. S. Decisões de

Estrutura de Capital de Empresas

Brasileiras: Um Estudo Empírico. In:

ASSEMBLEIA DO CONSELHO

LATINO-AMERICANO DE ESCOLAS

DE ADMINISTRAÇÃO - CLADEA, 37,

2002, Porto Alegre. Anais... Porto Alegre:

CLADEA 2002.
OLIVEIRA, V. A.; LEMES, S. Nível de convergência dos princípios contábeis brasileiros e norte-americanos às normas do IASB: uma contribuição para a adoção das IFRS por empresas brasileiras.

Revista Contabilidade \& Finanças, v. 22, n. 56, p.153-173, 2011.

OTUKA, D. A. G.; POKER JR., J. H.; KOSHIO, S. Processo decisório de estrutura de capital: um estudo de caso da CPFL Energia. In: SEMINÁRIOS EM ADMINISTRAÇÃO - SEMEAd, 15, 2012, São Paulo. Anais... São Paulo: FEA/USP, 2012.

PORTAL, M. T.; ZANI, J.; SILVA, C. E. Fricções financeiras e a substituição entre fundos internos e externos em companhias brasileiras de capital aberto. Revista de Contabilidade \& Finanças, v. 23, n. 58, p. 19-32, 2012.

PROCIANOY, J. L.; CASELANI, C. N. A emissão de ações como fonte de crescimento ou como fator de redução do risco financeiro: resultados empíricos.

Revista de Administração, v. 32, n. 3, p. 70-81, 1997.

; SCHNORRENBERGER, A. A

influência da estrutura de controle nas decisões de estrutura de capital das companhias brasileiras. Revista Brasileira de Economia, v. 58, n. 1, p. 121-146, 2004.

RAJAN, R. G.; ZINGALES, L. What do we know about capital structure? Some evidence from international data. The Journal of Finance, v. 50, n. 5, p. 14211460, 1995.

RIBEIRO, D. M.; REIS, L. M.; PINHEIRO, L. E. T. Impacto da mudança contábil no reconhecimento de ativos nas operações de arrendamento mercantil. In: CONGRESSO ASSOCIAÇÃO NACIONAL DOS PROGRAMAS DE PÓS-GRADUAÇÃO EM CIÊNCIAS 
CONTÁBEIS, 7, 2013, Fortaleza, Anais... Fortaleza: ANPCONT, 2013.

SEIDEL, A.; KUME, R. Contabilização das variações da necessidade de capital de giro. Revista Contabilidade \& Finanças - USP, São Paulo, n. 31, p. 66-77, 2003.

SHYAM-SUNDER, L.; MYERS, S. C. Testing static tradeoff against pecking order models of capital structure. Journal of Financial Economics, v. 51, p. 219 244, 1999.

SILVA, A. F.; VALLE, M. R. Análise da estrutura de endividamento: um estudo comparativo entre empresas brasileiras e americanas. Revista de Administração Contemporânea, v. 12, n. 1, p. 201-229, 2008.

SILVA, J. O. ; CARDOSO, R. S.; TOLEDO FILHO, J. R. Impacto da crise do subprime no endividamento das maiores empresas brasileiras. Revista Pensar Contábil, v. 12, p. 16-25, 2010.

SOARES. R. O.; KLOECKNER, G. O. Relações entre estrutura de propriedade e estrutura de capital no Brasil. In: ENCONTRO BRASILEIRO DE FINANÇAS, 6, 2006, Vitória. Anais... Vitória: SBFIN, 2006.

TERRA, P. R. S. Estrutura de capital e os fatores macroeconômicos na América Latina. Revista de Administração da Universidade de São Paulo - RAUSP, São Paulo, v. 42, n. 2, p. 192-204, 20. 